\title{
Compartment-Specific Modulation of GABAergic Synaptic Transmission by $\mu$-Opioid Receptor in the Mouse Striatum with Green Fluorescent Protein-Expressing Dopamine Islands
}

\author{
Masami Miura, ${ }^{1}$ Sachiko Saino-Saito, ${ }^{2}$ Masao Masuda, ${ }^{1}$ Kazuto Kobayashi, ${ }^{3}$ and Toshihiko Aosaki ${ }^{1}$ \\ ${ }^{1}$ Neural Circuits Dynamics Research Group, Tokyo Metropolitan Institute of Gerontology, Itabashi-ku, Tokyo 173-0015, Japan, ${ }^{2}$ Department of Anatomy \\ and Cell Biology, Yamagata University School of Medicine, Yamagata, Yamagata 990-9585, Japan, and ${ }^{3}$ Fukushima Medical University School of Medicine, \\ Fukushima, Fukushima 960-1295, Japan
}

\begin{abstract}
The striatum is a heterogeneous mosaic of two neurochemically, developmentally, and functionally distinct compartments: the $\mu$-opioid receptor (MOR)-enriched striosomes and the matrix. Preferential activation of the striosomes and persistent suppression of the matrix have recently been suggested to represent neural correlates of motor stereotypy. However, little is known concerning the physiological properties of the striosomes. We made patch-clamp recordings from medium spiny neurons in identified MOR-immunoreactive "dopamine islands" as striosomes in a slice preparation taken from transgenic mice expressing green fluorescent protein in tyrosine hydroxylase mRNA-containing neurons. Striosomal neurons differed electrophysiologically from cells in the matrix in having significantly less hyperpolarized resting membrane potentials and larger input resistances, suggesting developmental differences between the two types of cells. Moreover, corticostriatal EPSCs were inhibited by MOR activation to similar extents in the two compartments, although inhibition of IPSCs was observed only in the striosomes. This MOR-induced inhibition of IPSCs was presynaptically mediated, because MOR agonist invariably decreased IPSC amplitudes when postsynaptic G-protein was inactivated, significantly increased the paired-pulse ratio of the IPSCs, and decreased the frequency but not the amplitude of miniature IPSCs. These effects of MOR were mediated principally by 4 -aminopyridine-sensitive $\mathrm{K}^{+}$conductance via a cAMP-dependent pathway, which was further augmented by previous blockade of the protein kinase $\mathrm{C}$ cascade. These findings suggest that MOR activation by endogenous and/or exogenous MOR-selective opioid substances differentially regulates the activities of the striosome and matrix compartments and thus plays an important role in motivated behavior and learning.
\end{abstract}

Key words: basal ganglia; striatum; dopamine islands; $\mu$-opioid; striosomes/patches; GABA; GFP; nigrostriatal

\section{Introduction}

The striatum is a major input station of the basal ganglia and plays critically important roles in motor control, reinforcement learning, and drug addiction (Gerdeman et al., 2003). It appears homogeneous at a glance but is actually composed of two neurochemically distinguishable compartments: the striosomes (or patches) and the matrix. These two compartments differ in input-output connections and the concomitant specialization of their neurotransmitters and neuromodulators, suggesting unique but interdependent physiological functions of the respective compartments (Graybiel and Ragsdale, 1978; Herkenham and Pert, 1981; Graybiel, 1990; Gerfen, 1992). In fact, the strio-

\footnotetext{
Received April 16, 2007; revised July 26, 2007; accepted July 27, 2007.

This work was supported by grants from the Ministry of Education, Science, Sports, Culture, and Technology of Japan and the Smoking Research Foundation of Japan.

Correspondence should be addressed to Toshihiko Aosaki, 35-2, Sakae-cho, Itabashi-ku, Tokyo 173-0015, Japan. E-mail: aosaki@tmig.or.jp.

DOI:10.1523/JNEUROSCI.2993-07.2007

Copyright $\odot 2007$ Society for Neuroscience $\quad$ 0270-6474/07/279721-08\$15.00/0
}

somes by and large receive inputs from limbic system-related cortex and subcortical nuclei, whereas the matrix is innervated mostly by sensorimotor cortex (Donoghue and Herkenham, 1986; Graybiel, 1990; Gerfen, 1992). It has been found that stimulating electrodes contacting the striosomes of the rat sustain electrical self-stimulation behavior more reliably than electrodes in the matrix, suggesting reward-related functions for the striosomes (White and Hiroi, 1998). Moreover, Canales and Graybiel (2000) reported that the degree of motor stereotypies induced by psychomotor stimulants correlated with the amount by which activation in the striosomes exceeded activation in the matrix, suggesting that balanced interaction between the two compartments is of critical importance for maintenance of normal sensorimotor and cognitive processing. However, determination of the physiological underpinning of striosome functions has been greatly hampered by the small volume of the striosomes, which constitute only $10-15 \%$ of the striatum and are distributed in a "patchy" manner. One clue to striosome physiology is that the striosomes and the subcallosal streak are specifically rich in $\mu$-opioid receptors (MORs), whereas other subtypes of recep- 
tors, $\delta$ and $\kappa$, are distributed more homogeneously in the striatum (Mansour et al., 1995). K-selective dynorphin and $\mu$ - and $\delta$-selective enkephalin are released from the striatal medium spiny (MS) neurons of the "direct" striatonigral and "indirect" striatopallidal pathway, respectively. Physiological studies of effects of opioids in the striatum were first performed by Jiang and North (1992) and demonstrated that bath application of a $\mu$-selective agonist induced presynaptic inhibition of EPSPs but not IPSPs in primary neurons (MS neurons) of rat neostriatal slices. Subsequent studies reported that MOR activation suppressed high-voltage-activated $\mathrm{Ca}^{2+}$ current in acutely dissociated neostriatal neurons of the rat (Stefani et al., 1994), although it was found that not $\mathrm{Ca}^{2+}$ but $\mathrm{K}^{+}$conductances mainly mediated presynaptic inhibition of corticostriatal population spikes in rat neostriatal slices (Barral et al., 2003). However, the existence of MORs even in the matrix compartment, although in a very small amount, makes pharmacological approaches of this type inappropriate for the elucidation of striosome function.

In this study, we took advantage of the fact that the striosomes correspond to the dopamine islands and made whole-cell patchclamp recordings from identified compartments in slice preparations from a transgenic mouse expressing green fluorescent protein (GFP) under the control of the rat tyrosine hydroxylase (TH) gene promoter (TH-GFP mouse) (Matsushita et al., 2002). We obtained evidence suggesting that MOR activation differentially regulates the activities of the striosome and matrix compartments.

\section{Materials and Methods}

Slice preparation and electrophysiology. All experimental procedures were performed in accordance with the Animal Welfare Guideline of the Tokyo Metropolitan Institute of Gerontology. Coronal corticostriatal slices $(250 \mu \mathrm{m})$ were obtained from TH-GFP mice aged postnatal day 12 (P12) to P32. Extracellular artificial CSF (ACSF) containing (in mM) $124 \mathrm{NaCl}$, $3 \mathrm{KCl}, 2.4 \mathrm{CaCl}_{2}, 1.2 \mathrm{MgCl}_{2}, 26 \mathrm{NaHCO}_{3}, 1 \mathrm{NaH}_{2} \mathrm{PO}_{4}$, and 10 D-glucose was saturated with $95 \% \mathrm{O}_{2} / 5 \% \mathrm{CO}_{2}, \mathrm{pH} 7.4$, and warmed to $32^{\circ} \mathrm{C}$. Whole-cell patch-clamp recordings were performed using an EPC 8 (HEKA Electronik, Lambrecht, Germany) with infrared-differential interference contrast (IR-DIC) visualization using a fluorescence microscope (BX50WI; Olympus, Tokyo, Japan). Patch pipettes (3-5 M $\Omega$ ) were filled with a solution containing (in $\mathrm{mM}$ ) $90 \mathrm{~K}$-gluconate, $45 \mathrm{KCl}, 5 \mathrm{NaCl}$, $2 \mathrm{MgCl}_{2}, 10$ HEPES, $4 \mathrm{Na}_{2}$-ATP, $0.3 \mathrm{GTP}, 0.1$ EGTA, and 0.5\% biocytin (brought to $\mathrm{pH} 7.3$ with $\mathrm{KOH}$; osmolarity, 300-310 mOsm; equilibrium potential of chloride, $-26 \mathrm{mV}$ ). The liquid junction potential of the solution was $10 \mathrm{mV}$ and corrected. Input resistance was calculated with injected current and membrane potentials of approximately $-80 \mathrm{mV}$. Evoked currents and miniature IPSCs (mIPSCs) were recorded at a holding potential of $-90 \mathrm{mV}$. If series resistance changed by $>15 \%$, the experiment was discarded. Signals were filtered at $5 \mathrm{kHz}$, digitized at 20 $\mathrm{kHz}$, and acquired using PULSE (HEKA Electronik). In the case of mIPSCs, tetrodotoxin (TTX) $(1 \mu \mathrm{M})$ was added to the bath. Data for mIPSCs were collected continuously for 15 min using PowerLab (AD Instruments, Castle Hill, Australia) and analyzed with Mini Analysis (Synaptosoft, Decatur, GA). Unless stated otherwise, drugs were bath-applied. All drugs were purchased from Sigma (St. Louis, MO), except D- (-)-2amino-5-phosphonopentanoic acid (AP-5; Tocris Bioscience, Bristol, UK). All values are mean \pm SEM. The statistical significance of differences was assessed by paired or unpaired Student's $t$ tests.

GFP appeared to persist long after TH immunoreactivity could no longer be used as a marker for the striosomes. We therefore identified brighter areas with GFP as the dopamine islands, that is, the striosomes, under the fluorescence microscope, moved the stage to center on one of the striosomes, and then switched to IR-DIC to find an MS neuron. After recording, brighter areas with GFP were confirmed to correspond to MOR-rich areas, as described below. Experiments on striosomes and matrix were alternately performed on the same day.
Immunohistochemistry. Tissue slices containing biocytin-filled cells were fixed by immersion in $4 \%$ paraformaldehyde in $0.1 \mathrm{M}$ phosphate buffer (PB), pH 7.4, for several hours. After all slices were washed in 0.1 $\mathrm{M} P B$, they were incubated with Alexa 405-conjugated streptavidin (Invitrogen, Eugene, OR) diluted 1:200 with $0.1 \mathrm{M}$ PB containing $0.5 \%$ Triton X-100 (TX) for $60 \mathrm{~min}$ on a shaker at room temperature. The slices were washed in $0.05 \mathrm{M}$ Tris-buffered saline (TBS) and incubated with $20 \%$ normal goat serum in 0.05 M TBS containing $2 \%$ bovine serum albumin and $0.5 \%$ TX for $60 \mathrm{~min}$ at room temperature. The slices were allowed to react with rabbit antiserum to MOR [AB5511, diluted 1:500 (Millipore, Billerica, MA); or \#24216, diluted 1:500 (ImmunoStar, Hudson, WI)] as the primary antibody in $0.05 \mathrm{M}$ TBS containing $0.5 \%$ TX for $24-48 \mathrm{~h}$ at $4^{\circ} \mathrm{C}$. After washing, the slices were allowed to react with secondary antibodies [cyanine 3-conjugated goat anti-rabbit IgGs, diluted 1:800 (Jackson ImmunoResearch, West Grove, PA)] in 0.05 м TBS for $3 \mathrm{~h}$ at room temperature. In the experiment shown in Figure $1 g-i$, Alexa 488-conjugated streptavidin (diluted 1:500; Invitrogen) and 4',6diamidino-2-phenylindole dihydrochloride (DAPI; $1 \mu \mathrm{g} / \mathrm{ml}$; Invitrogen) were used for nuclear staining. Images were obtained with a macro zoom fluorescence microscope (MVX10; Olympus) and a confocal laserscanning microscope (CLSM; LSM5 PASCAL; Zeiss, Oberkochen, Germany).

\section{Results}

Patchy distributions of zones immunoreactive for TH and GFP in the striatum of a TH-GFP mouse at P7 are shown separately in adjacent sections in Figure 1, $a$ and $b$, respectively. These GFPpositive and $\mathrm{TH}$-immunoreactive "dopamine islands" are composed of axons from dopamine neurons of the substantia nigra and do not contain any intrinsic dopamine cells. It has been established that the dopamine islands correspond to the striosome compartments (Graybiel et al., 1981; Herkenham and Pert, 1981). The striosomes were thus identified as bright GFP-rich areas under a fluorescence microscope (Fig. 1c). Whole-cell patch-clamp recordings were subsequently made from MS cells in the bright striosomal compartments, and these areas were confirmed to be immunoreactive for MOR after recordings (Fig. 1d). All the cells were filled with and stained for biocytin, and their locations were checked to determine the compartments to which they belonged (Fig. $1 c-f$ ). As shown in Figure $1, f$ and $g$, dendritic extensions of the biocytin-filled neurons were mostly restricted to the striosomes to which the somata belonged, in agreement with previous studies (Kawaguchi et al., 1989; Walker et al., 1993). Colocalization of biocytin and MOR in the recorded neurons was also checked immunohistochemically (Fig. 1g,h). MORimmunoreactive materials were clearly localized inside the cell body but outside the DAPI-labeled nucleus of biocytin-filled neurons.

In total, 119 striosomal cells and 42 matrix cells were recorded in this study. Inward rectification in response to current pulse injection, a finding typical of MS cells, was observed in both striosomal and matrix cells. However, the slow ramp depolarization was inconspicuous in the striosomal cells at P15 (Fig. 2a). The resting membrane potential $\left(V_{\text {rest }}\right)$ was significantly higher at ages P12-P18 (Fig. $2 b$ ) (striosomes, $-83.7 \pm 0.67 \mathrm{mV}, n=83$; matrix, $-87.7 \pm 0.60 \mathrm{mV}, n=30 ; p<0.01)$. In addition, the input resistance $\left(R_{\mathrm{m}}\right)$ of striosomal cells was higher than that of matrix cells during P12-P18 (striosomes, $259 \pm 9.6 \mathrm{M} \Omega, n=83$; matrix, $170 \pm 11.1 \mathrm{M} \Omega, n=30 ; p<0.01$ ) and P19-P28 (striosomes, $207 \pm 10.0 \mathrm{M} \Omega ; n=36$; matrix, $116 \pm 11.6 \mathrm{M} \Omega, n=12$; $p<0.01$ ), suggesting developmental differences between the striosomes and matrix. In contrast, there were no differences in the threshold, amplitude, or half-width of spikes (striosomes, $-48.6 \pm 0.23 \mathrm{mV}, 72.0 \pm 0.83 \mathrm{mV}, 1.14 \pm 0.023 \mathrm{~ms}$; matrix, $-49.0 \pm 0.43 \mathrm{mV}, 74.7 \pm 1.30 \mathrm{mV}, 0.99 \pm 0.039 \mathrm{~ms})$. 


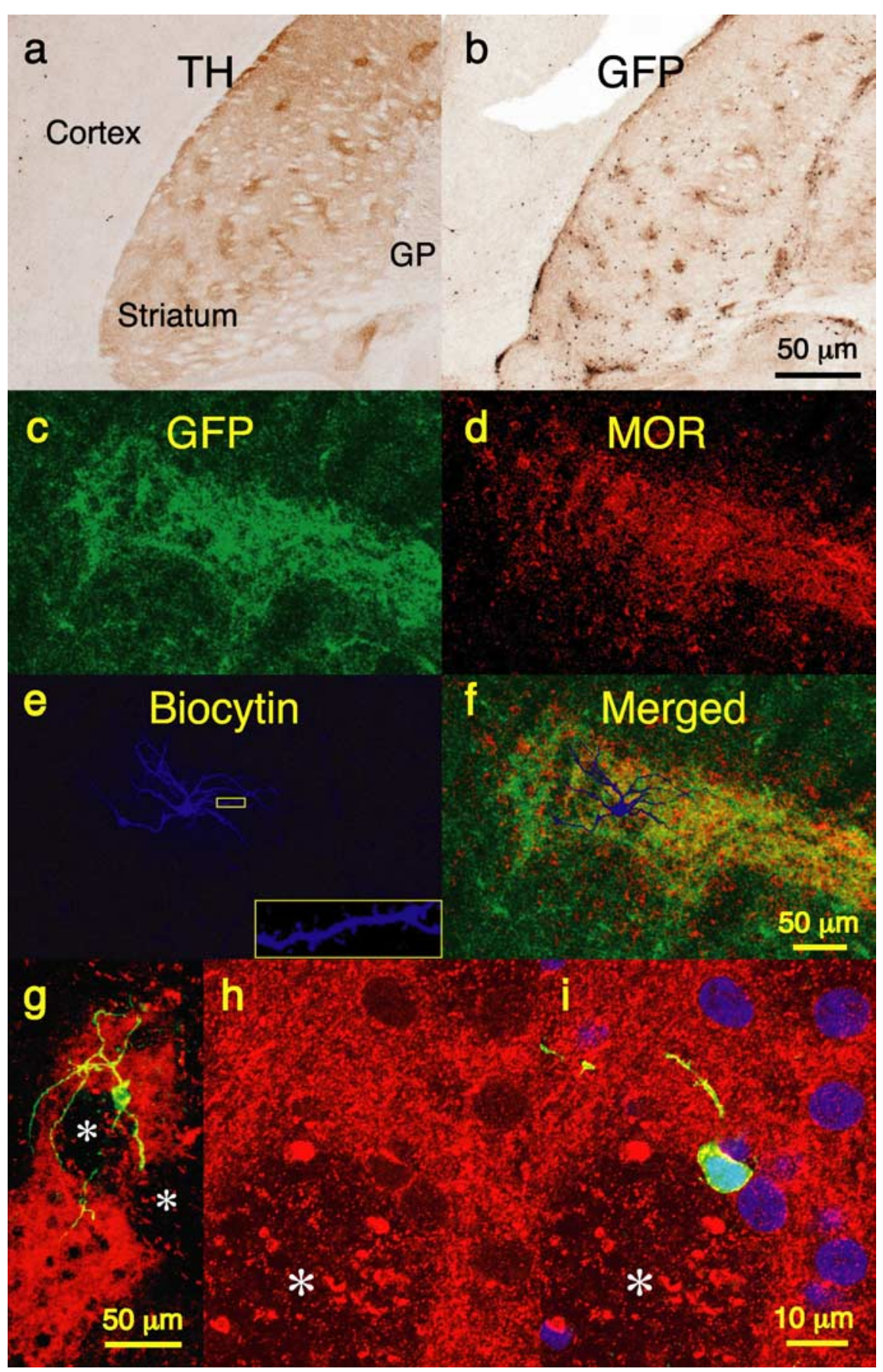

Figure 1. Immunohistochemically identified striosome/matrix compartments of TH-GFP mice. $\boldsymbol{a}, \boldsymbol{b}$, Photomicrographs show patchy immunoreactivity for TH $(\boldsymbol{a})$ and GFP $(\boldsymbol{b})$ in horizontal sections at P7. The patchy appearance of dopamine islands is attributable to axons of nigrostriatal dopaminergic neurons which are TH immunoreactive. № TH-positive neurons were present in the dopamine islands. Left-right, Rostral-caudal; up- down, lateral-medial. c-f, CLSM images at P16. A biocytin-injected cell ( $\boldsymbol{e}$, blue) is located in a GFP-positive ( $\boldsymbol{c}$, green) and MOR-immunoreactive $(\boldsymbol{d}$, red) area. The boxed area in $\boldsymbol{e}$ is shown at a higher magnification in the inset to illustrate spiny dendrites. The projection image of the cell is overlaid with the merged photomicrograph $(\boldsymbol{f})$. The dendrites of the cell are restricted to the MOR-immunoreactive dopamine island. Note that there are no GFPpositive neurons in the dopamine islands. MOR-immunoreactive materials are diffusely scattered in the matrix but densely clustered in a striosome. $g$, Projection image of another biocytin-filled cell (green) in an MOR-immunoreactive striosome (red). Asterisks indicate fiber bundles. The dendritic extension of the cell is mostly confined to the striosome. $\boldsymbol{h}$, Enlarged photomicrograph of $\boldsymbol{g}$. Locations of cell nuclei can be identified by lack of MOR immunoreactivity. $\boldsymbol{i}$, Merged. Nuclei (blue) were stained with DAPI. MOR-immunoreactive materials can be seen in yellow in the soma and dendrites of the recorded cell.

Electron microscopic analysis of the striosomes indicated that MOR-like immunoreactivity was present in dendrites, dendritic spines, perikarya, and axon terminals of MS cells (Wang et al., 1996). Indeed, a small degree of hyperpolarization $(3.8 \mathrm{mV})$ was observed in 17 of 93 cells with application of the MOR agonist [D-Ala ${ }^{2}-\mathrm{N}-\mathrm{Me}-\mathrm{Phe}^{4}$, Gly-ol ${ }^{5}$ ]-enkephalin (DAMGO) by Jiang and North (1992) using a rat slice preparation. This large sampling number (93 cells) increases the probability of sampling striosomal cells, suggesting that the DAMGO-responsive cells (17 cells) might have been present in the striosomes. We therefore examined the effects of the MOR agonist DAMGO on the $V_{\text {rest }}$ of striosomal cells in current-clamp mode. Bath-applied DAMGO ( $1 \mu \mathrm{M}, 3-5 \mathrm{~min})$ hyperpolarized 3 of 10 cells by $2-5 \mathrm{mV}$ (data not shown). This effect was very small in our recording configuration, perhaps because the reversal potential of $\mathrm{K}^{+}$channel current coupled to MOR was close enough to $V_{\text {rest }}$ that the voltage deflections appeared minimal. We therefore did not extensively examine the effects of DAMGO on membrane potentials in the present study. Additional examinations of such effects are clearly needed.

We next studied the effects of DAMGO on excitatory corticostriatal inputs to the striatal compartments. We stimulated the corticostriatal inputs with a bipolar tungsten electrode placed in the white matter. In the presence of (-)-bicuculline methiodide (BMI), a specific $\mathrm{GABA}_{\mathrm{A}}$ receptor antagonist, glutamatergic EPSCs of a striosomal cell were suppressed by DAMGO and slowly recovered after washout of the drug (Fig. 3a). However, there was no significant difference in the extent of inhibition of EPSCs between the two compartments (striosomes, $12.0 \pm 5.0 \%, n=21$; matrix, $8.6 \pm 4.5 \%, n=12$ ) (Fig. $3 b$ ).

MORs are located at the presynaptic GABA terminals in the striosomes and form symmetrical synapses with the dendritic shaft (Wang et al., 1996; Wang and Pickel, 2001). MORs might thus modulate GABAergic synaptic transmission in compartment-specific manner. We examined the effects of DAMGO on IPSCs evoked with a glass microelectrode (30$150 \mu \mathrm{A}, 100 \mu \mathrm{s})$ placed near the MS cells $(120-180 \mu \mathrm{m})$ in the presence of 6-cyano7-nitroquinoxaline-2,3-dione (CNQX), an AMPA and kainate receptor antagonist, and AP-5, a selective NMDA antagonist. The IPSCs were GABAergic because they were completely blocked by BMI $(10 \mu \mathrm{M})$ at the end of the experiment (Fig. 4a). When a cell was in a striosome, and in addition the stimulation electrode was placed in the same striosome, bath-applied DAMGO (1 $\mu \mathrm{M}, 3 \mathrm{~min})$ reversibly and dose-dependently reduced the IPSCs, and this effect of DAMGO was completely blocked by D-Phe-Cys-Tyr-D-Trp-Orn-Thr-Pen-Thr- $\mathrm{NH}_{2}$ (CTOP) $(1 \mu \mathrm{M})$, an MOR antagonist (Fig. 4) (DAMGO, $18.7 \pm 3.6 \%, n=55$; 
a

Striosome
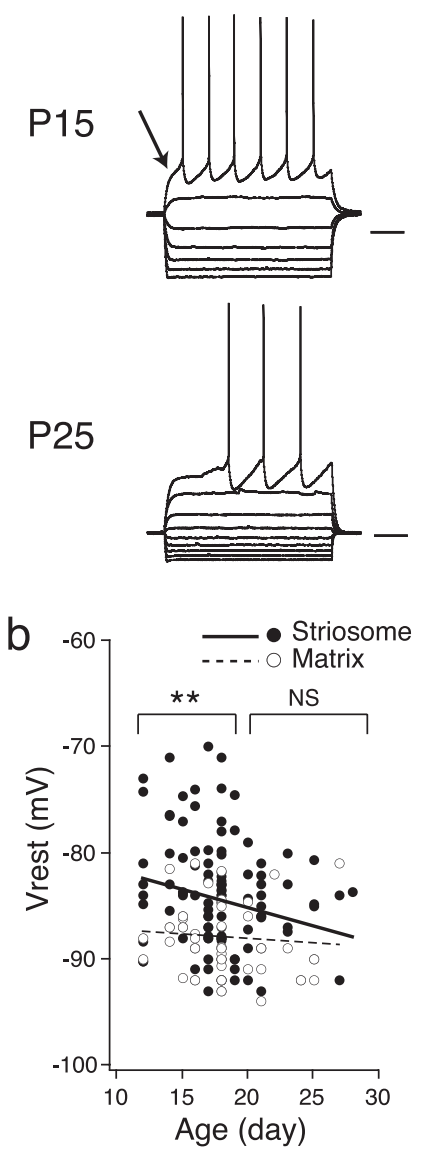
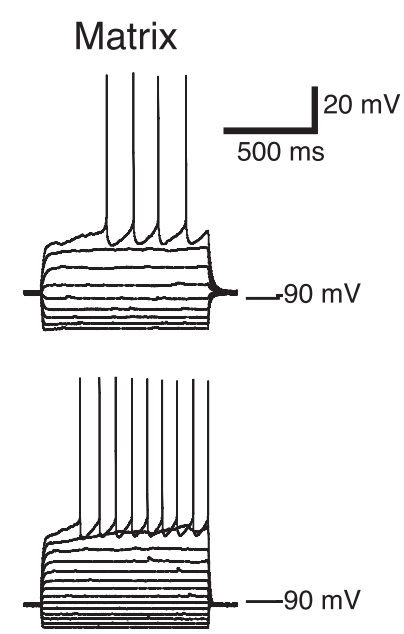

Figure 2. Electrophysiological properties of MS cells in the striosome and matrix compartments. $\boldsymbol{a}$, Representative firing patterns of MS cells in slices obtained from TH-GFP mice aged P15 and P25. Striosomal cells exhibited more depolarized resting membrane potential $\left(V_{\text {rest }}\right)$ and higher input resistance $\left(R_{\mathrm{m}}\right)$. Note the lack of slow ramp depolarization (arrow). $\boldsymbol{b}, V_{\text {rest }}$ and $R_{\mathrm{m}}$ are plotted against the ages of TH-GFP mice (striosome, $n=119$; matrix, $n=42$ ). $V_{\text {rest }}$ of striosomal cells significantly differed from that of matrix cells during P12-P18 (striosomes, $n=$ 83; matrix, $n=30$; ${ }^{* *} p<0.01$ ), whereas the $R_{\mathrm{m}}$ of striosomal cells was larger than that of matrix cells during P12-P28. NS, Not significant.

CTOP, $-2.3 \pm 3.5 \%, n=6 ; p<0.01$ ), indicating that MOR activation suppressed IPSCs. In sharp contrast, DAMGO had no effect on IPSCs when MS cells and the stimulation electrode were in the matrix $(-3.0 \pm 5.5 \%, n=18)$. Furthermore, we examined whether endogenously and concomitantly released dopamine had modulated the effects of DAMGO on evoked IPSCs, because nigral dopaminergic neurons preferentially innervate the striosomes in early developmental stages. However, combined application of dopamine receptor antagonists, including $10 \mu \mathrm{M}$ SCH23390 $[R(+)$-7-chloro-8-hydroxy-3-methyl-1-phenyl2,3,4,5-tetrahydro- $1 \mathrm{H}$-3-benzazepine] for dopamine $\mathrm{D}_{1}$-like receptors and $10 \mu \mathrm{M}$ sulpiride for $\mathrm{D}_{2}$-like receptors, did not alter the effects of DAMGO $(-19.6 \pm 10.2 \%, n=8)$ (Fig. $4 c$ ).

It was reported previously by Jiang and North (1992) that GABAergic IPSPs of the rat striatum were suppressed in all five of the cells tested by activation of $\delta$-opioid receptor (DOR) but not by MOR activation (none of five cells tested). We therefore tested the effect of a DOR agonist, [D-Pen ${ }^{2,5}$ ]-enkephalin (DPDPE), on the IPSCs in the striosome and matrix compartments. Bathapplied DPDPE $(1 \mu \mathrm{M})$ suppressed the amplitude of IPSCs by $15.5 \pm 5.7 \%(n=8)$ in the striosomes and by $20.7 \pm 6.4 \%(n=$ 8 ) in the matrix (data not shown). There was no significant dif- a

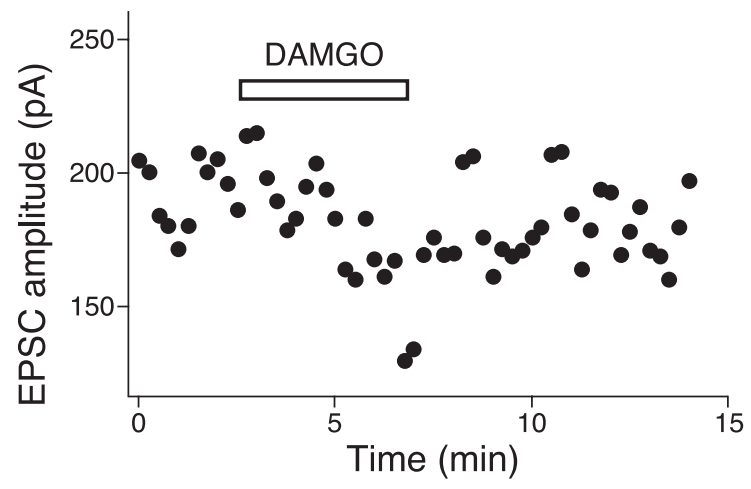

b
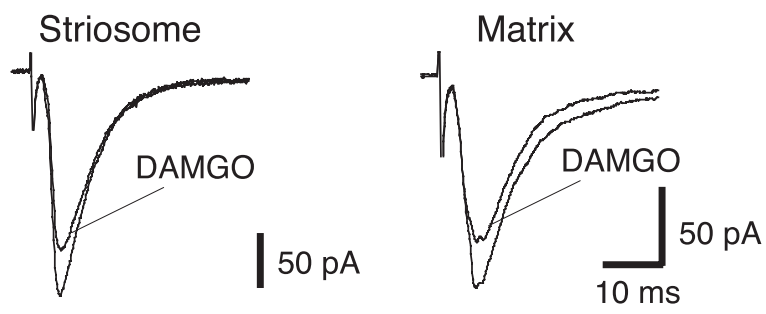

Figure 3. Corticostriatal excitatory inputs were reduced by DAMGO in striosome and matrix compartments. $\boldsymbol{a}$, EPSCs recorded from a striosomal MS cell (holding potential, $-90 \mathrm{mV}$ ) in the presence of BMI, a $\mathrm{GABA}_{\mathrm{A}}$ receptor antagonist $(10 \mu \mathrm{M})$. DAMGO $(1 \mu \mathrm{M})$, an MOR agonist, was applied to the bath at the time indicated by an open bar. $\boldsymbol{b}$, Representative current traces. The traces are averages of three consecutive traces. DAMGO decreased the amplitude of EPSCs in both striosome and matrix MS cells.

ference in the extent of suppression between the two. Thus, suppression of IPSCs by DOR activation was found in both compartments, although effects of DAMGO on IPSCs were observed only in the striosomes in our study. This apparent discrepancy in findings between our and their study on the effects of DAMGO on IPSPs/IPSCs can be easily explained by the animal they used. Because the matrix occupies $>80 \%$ of the striatum, random sampling from rat striatal slices would greatly favor matrix cells if sampling number were small. If most of the cells they obtained were from the matrix, their findings are consistent with our own.

A pair of IPSCs were elicited by two successive stimuli at an interval of $100 \mathrm{~ms}$ and the paired-pulse ratio (PPR), the ratio of the amplitude of the second IPSC to the first, was monitored before and after DAMGO $(1 \mu \mathrm{M})$ application. We found that the striosomal cells exhibited a reversible and significant increase in PPR (Fig. 5a,b) (control, 92.5 土 3.5\%; DAMGO, $106.6 \pm 8.9 \%$; $n=54, p<0.05$ ), suggesting a presynaptic effect of MOR. However, DAMGO did not change the PPR in the matrix (Fig. $5 b$ ). To further confirm the presynaptic effect of DAMGO, GDP- $\beta$-S (1.5 $\mathrm{mM}$ ) was loaded in the cell through a recoding pipette to inactivate the postsynaptic MOR signaling cascade. GDP- $\beta$-S has been frequently used to inactivate postsynaptic G-protein-coupled pathways at concentrations of $0.2-2.0 \mathrm{~mm}$ in the striatum (Hsu et al., 1997; Norenberg et al., 1997; Narushima et al., 2007), substantia gelatinosa (Schneider et al., 1998), cerebellum (OhnoShosaku et al., 2003), and other brain structures. In the presence of GDP- $\beta$-S in the patch pipette, DAMGO nevertheless reduced IPSCs by $15.7 \pm 6.7 \%(n=5$; data not shown $)$.

We then turned to mIPSC analysis of striosomal cells. DAMGO $(1 \mu \mathrm{M})$ increased the interevent interval of mIPSCs without changing their amplitude (Fig. 5c) (Kolmogorov-Smirnov two-sample test, $p<0.0001)$. In total, we recorded mIPSCs 


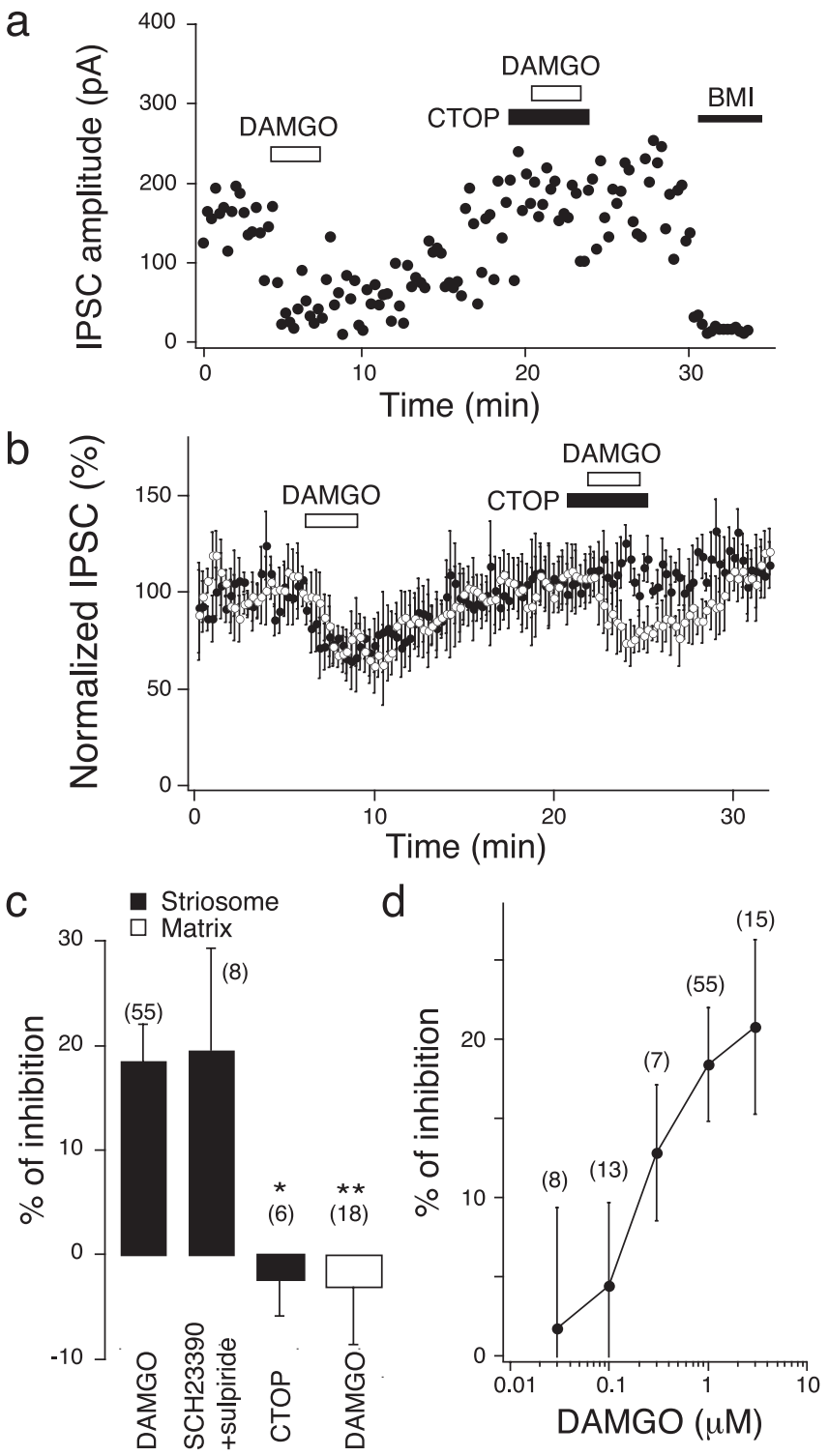

Figure 4. GABAergic IPSCs of striosomal MS cells were reduced by activation of $\mu$-opioid receptors. $\boldsymbol{a}$, IPSCs recorded from a striosomal MS cell (holding potential, -90 $\mathrm{mV})$ in the presence of CNQX (10 $\mu \mathrm{m})$ and AP-5 (25 $\mu \mathrm{m})$. DAMGO (1 $\mu \mathrm{m}, 3$ min; open bars) reduced IPSCs in the absence of the MOR antagonist CTOP (1 $\mu \mathrm{M})$. At the end of the experiment, BMI was bath applied to confirm that the IPSCs were $G_{A B A_{A}}$ receptor mediated. $\boldsymbol{b}$, IPSCs recorded in the presence (closed circle; $n=6$ ) or absence (open circle; $n=$ 6) of CTOP $(0.3-1 \mu \mathrm{M})$. C, DAMGO reduced IPSCs only in the striosomes and not in matrix $\left({ }^{* *} p<0.01\right)$. The inhibitory effect of DAMG0 was completely blocked by CTOP $\left({ }^{*} p<\right.$ 0.05). Antagonists of dopamine receptors, including $R(+)$-7-chloro-8-hydroxy-3methyl-1-phenyl-2,3,4,5-tetrahydro-1 H-3-benzazepine (SCH23390; $10 \mu \mathrm{m}$ ) for $\mathrm{D}_{1}$-like and sulpiride $(10 \mu \mathrm{m})$ for $D_{2}$-like receptors, did not alter the effects of DAMGO.d, Dose dependence of the effect of DAMGO on the IPSCs of striosomal cells.

from eight striosomal cells and seven matrix cells (P16-P17; three mice). DAMGO reduced the frequency of mIPSCs only in the striosomes (Fig. $5 d$ ) (control, $1.47 \pm 0.34 \mathrm{~Hz}$; DAMGO, $1.09 \pm 0.23 \mathrm{~Hz} ; n=8 ; p<0.01$, paired $t$ test). These findings clearly indicate that MOR inhibition of GABAergic IPSCs in the striosomes was presynaptic.

Interestingly, the PPR of the striosomal cells was larger than that of the matrix cells even before DAMGO application (Fig. 5b) (striosomes, $92.5 \pm 3.5 \%, n=54$; matrix, $74.3 \pm 3.8 \%, n=16$; $p<0.01)$. There was also a tendency for the mean frequency of the striosomal cells to be lower than that of the matrix cells, although the difference between cell types did not reach statistical significance (Fig. $5 d$ ), presumably because of large variation in frequency. We then added data from three more mice at P14-P15 and examined the mIPSCs of six mice in total at P14-P17 to determine whether the frequency of mIPSCs differed between the two cell types. The frequency for striosomal cells $(1.02 \pm 0.19 \mathrm{~Hz}$; $n=17)$ was significantly lower than that for matrix cells (1.97 \pm $0.33 \mathrm{~Hz}, n=17 ; p<0.01$ ), suggesting that the striosomal cells had a lower probability of release. To explore whether endogenous enkephalin was tonically released and had partially suppressed GABA release via MOR activation in the striosomes, we recorded mIPSCs at P17-P18 in the presence or absence of CTOP $(1 \mu \mathrm{M})$. The mIPSCs recorded in the presence of CTOP were different in neither frequency (control, $1.68 \pm 0.22 \mathrm{~Hz}$; CTOP, $1.79 \pm 0.25 \mathrm{~Hz} ; p=0.113 ; n=9$ ) nor amplitude (control, $20.3 \pm$ $2.3 \mathrm{pA}$; CTOP, $20.5 \pm 2.0 \mathrm{pA} ; n=9$ ) from those obtained without CTOP. Therefore, tonic suppression of GABA release by endogenous enkephalin in the striosomes may not be the reason why the probability of release was lower in the striosomes.

Presynaptic inhibition of corticostriatal excitatory inputs by MOR activation was proven to be mediated by $\mathrm{K}^{+}$channel modulation rather than voltage-activated $\mathrm{Ca}^{2+}$ channels, in the rat striatum (Barral et al., 2003). We therefore applied 4-aminopyridine (4-AP) $(100 \mu \mathrm{M})$ to the bath to block 4-APsensitive $\mathrm{K}^{+}$channels and found that the amplitude of IPSCs was significantly increased by 4 -AP $(202 \pm 74 \% ; n=5 ; p<0.05$, paired $t$ test). However, additional application of DAMGO (1 $\mu \mathrm{M}, 5 \mathrm{~min}$ ) did not suppress the augmented IPSCs (Fig. 6a,d) $(-1.2 \pm 8.0 \% ; n=5)$, indicating that MORs affected GABA release mainly through 4 -AP-sensitive $\mathrm{K}^{+}$channels.

Finally, we examined the MOR signaling cascade. Preapplication of 9-(tetrahydro-2' -furyl)adenine (SQ22536) (100-300 $\mu \mathrm{M})$, an inhibitor of adenylyl cyclase, or H-89 (10 $\mu \mathrm{M})$, an inhibitor of cAMP-dependent protein kinase A (PKA), reduced the suppression of IPSCs by DAMGO (Fig. $6 b, d$ ). SQ22536 and H-89 themselves decreased the baseline amplitude of GABAergic IPSCs to $-28.4 \pm 12.7 \%(n=6)$ and $-29.6 \pm 8.9 \%(n=6)$ of the control, respectively, within $15 \mathrm{~min}$, as described previously (Miura et al., 2002; Shin et al., 2003). Subsequent application of DAMGO, however, had a small but not significant effect on the IPSCs. Thus, SQ22536 and H-89 appeared to occlude the effects of DAMGO. In contrast, chelerythrine $(3 \mu \mathrm{M})$, an inhibitor of protein kinase $\mathrm{C}(\mathrm{PKC})$, significantly enhanced the effect of DAMGO (Fig. $6 c, d$ ) (DAMGO, $20.2 \pm 5.5 \%, n=29$; chelerythrine, $34.5 \pm 7.1 \%, n=8 ; p<0.05)$. Chelerythrine itself did not alter the baseline amplitude $(6.2 \pm 8.5 \%, n=8)$. Involvement of the arachidonic acid cascade in the effect of MOR on IPSCs appeared unlikely, because the lipoxygenase inhibitor NDGA $[1,4-$ bis (3,4-dihydroxyphenyl)-2,3-dimethylbutane] (10 $\mu \mathrm{M})$ had no effect on the DAMGO-induced inhibition of IPSCs (Fig. $6 d$ ) $(20.6 \pm 10.3 \%, n=7)$.

\section{Discussion}

By whole-cell patch-clamp recordings from identified striatal compartments, we obtained evidence for the first time that (1) striosomal neurons differ electrophysiologically from cells in the matrix in having significantly less hyperpolarized resting membrane potentials and larger input resistances, and (2) although corticostriatal EPSCs were inhibited by MOR activation to similar extents in the two compartments, inhibition of IPSCs by MOR was observed only in the striosomes. 


\section{Dopamine islands as a marker} of striosomes

Early in development, the striosomes are called "dopamine islands" because nigrostriatal dopamine neurons innervate the striatum and form $\mathrm{TH}$-immunoreactive patches. Although $\mathrm{TH}$ immunoreactive neurons are absent, THimmunoreactive and thus GFP-positive axonal fibers are visible in the striosomes of our TH-GFP mice. We therefore identified dopamine islands as striosomal compartments. The dopamine islands of the developing striatum correspond to the acetylcholinesterase-poor and MORenriched striosomes/patches (Graybiel et al., 1981; Herkenham and Pert, 1981). In the rat, the striosomal neurons are born at embryonic day 12 (E12) and only become patchy as the matrix neurons generated at E18-E21 migrate out into the striatum (Edley and Herkenham, 1984; Fishell and van der Kooy, 1987). Although MOR remains patchy in the adult, a second wave of nigrostriatal dopamine innervation during the first postnatal week changes the distribution of TH-immunoreactive zones from patchy to homogeneous again after P16. Nevertheless, in TH-GFP mice, visibility of the dopamine islands continues until approximately P35, probably because of overproduction and/or protracted degradation of GFP protein, and enables our electrophysiological examination of MS cells in the striosomes of the developing striatum in brain slices.

\section{Striosomal cells are} electrophysiologically different from matrix cells

The passive membrane properties of MS cells of the adult include a very hyperpolarized membrane potential, ramp-like depolarization, and a pronounced, fast inward rectification that results in a relatively low input resistance at rest (Wilson, 2004). Previous studies with immunohistochemistry (Kawaguchi et al., 1989) or single-cell reverse transcription-PCR

(Venance and Glowinski, 2003) revealed no electrophysiological differences in any of these parameters between striosomal and matrix cells. Our findings, however, indicated that these cells differ in certain aspects electrophysiologically. First, the resting membrane potential of striosomal cells was significantly more depolarized than that of matrix cells, whereas both types of cells tended to become more hyperpolarized during P12-P28. Second, the input resistance of striosomal cells was larger than that of matrix cells, although both became progressively larger, and inward rectification became more marked. Interestingly, gradual decrease in resting membrane potential and increase in input resistance during postnatal development were reported previously in MS cells in de facto matrix (Tepper et al., 1998). This protracted development of the striosomal cells also parallels the $n=8$; matrix,$\left.n=7 ;{ }^{* *} p<0.01\right)$. b

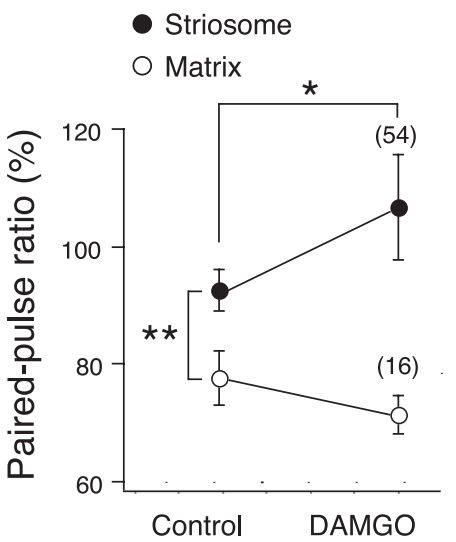

d
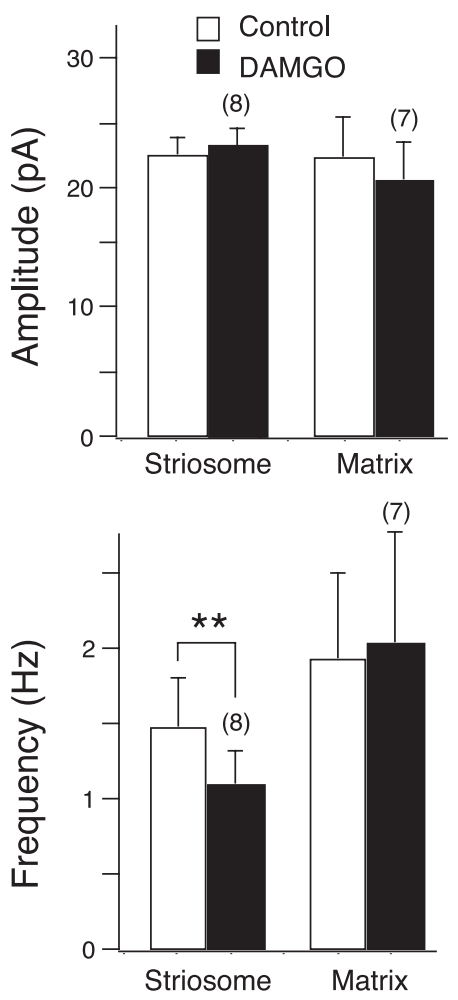

Figure 5. Inhibition of IPSCs by MOR in the striosomes was presynaptic. $\boldsymbol{a}, \mathrm{DAMGO}(1 \mu \mathrm{M})$ decreased the amplitude of IPSCs and (closed circles; $n=54$ ) and matrix (open circles; $n=18$ ). c (Cumulative histograms of probability vs amplitude (top) or interevent for 200 s just before (solid line) and after (dotted line) DAMGO application. $d$, Mean amplitude and frequency of mIPSCs (striosome,

recent findings that in the adult primate brain, striosomes are more intensely stained than the matrix for Bcl-2, an antiapoptotic protein and marker of neuronal immaturity (Levesque et al., 2004), and that immunostaining for glutamic acid decarboxylase, the enzyme that synthesizes GABA and thus controls progenitor cell development in the postnatal subventricular zone, is more intense in the striosomes than in the matrix of the mouse brain (Liu et al., 2005). Thus, striosomal cells may differ developmentally from matrix cells even in the postnatal period.

\section{Inhibition of EPSCs by $\mu$-opioids is observed throughout} the striatum

As described previously for the rat striatum (Jiang and North, 1992; Barral et al., 2003), we found that application of the selec- 
a

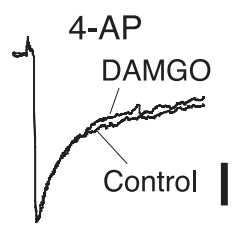

b

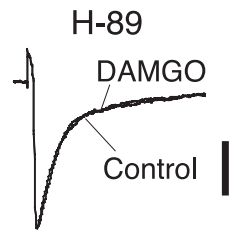

C

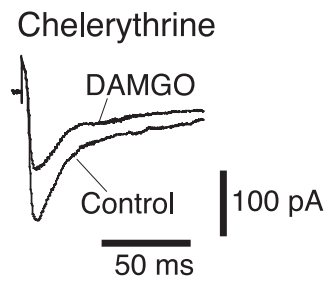

d

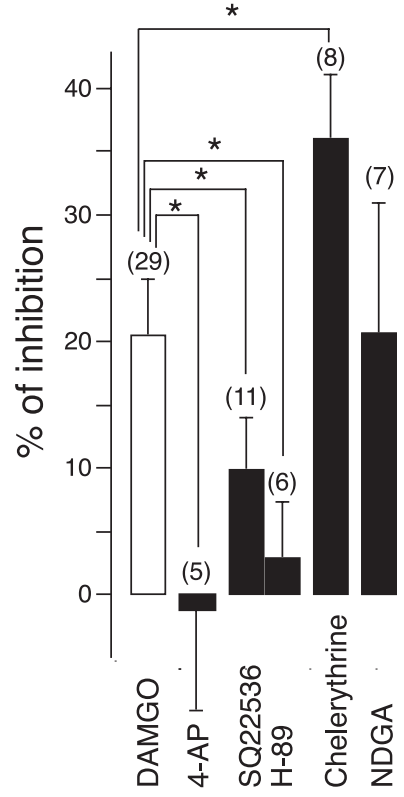

Figure 6. PKA signaling cascade was involved in the MOR inhibition of IPSCs. $\boldsymbol{a}-\boldsymbol{c}$, Representative current traces in the presence or absence of $100 \mu \mathrm{M} 4-\mathrm{AP}(\boldsymbol{a}), 10 \mu \mathrm{M} \mathrm{H}-89(\boldsymbol{b})$, and 3 $\mu \mathrm{m}$ chelerythrine $(\boldsymbol{c})$. $\boldsymbol{d}$, Slices were preincubated for 60-120 min with SQ22536 (100-300 $\mu \mathrm{M}), \mathrm{H}-89$, or 1,4-bis(3,4-dihydroxyphenyl)-2,3-dimethylbutane (NDGA; $10 \mu \mathrm{m})$. Other drugs were bath applied $10 \mathrm{~min}$ before the application of DAMG0.

tive MOR agonist DAMGO suppressed corticostriatal EPSCs. However, this suppression was $10 \%$ at most and was found in only half of the cells tested. This indicates that a substantial portion of each EPSC was evoked by glutamate released from a set of presynaptic fibers that were devoid of MORs, because it has been reported previously that only $14 \%$ of prefrontal corticostriatal axons and axon terminals contained immunogold silver particles for MOR in the striosomes (Wang and Pickel, 1998). More remarkably, inhibition of EPSCs by MOR was not observed in the striosomes alone but also in the matrix compartment, and to a similar degree. This fits well with the recent anatomical finding that $\mu$ receptor mRNA and binding sites are strongly expressed in the matrix compartment, which diminishes in size but persists during the early postnatal period (Winzer-Serhan et al., 2003).

\section{Presynaptic inhibition of IPSCs by $\mu$-opioids in the striosomes}

The effects of opioids on the IPSCs or IPSPs evoked by intrastriatal stimulation have never been carefully studied. Jiang and North (1992) tested the effects of opioid agonists on the IPSPs observed in a small number of MS cells (up to five cells) and concluded that the IPSPs were selectively reduced by $\delta$-opioid receptors. However, considering the limited size of the striosomes, these findings should be interpreted as those obtained with sampling in the matrix. In the present study, we found for the first time that the GABAergic IPSCs were suppressed by DAMGO selectively in the striosomes but not in the matrix. The suppression by DAMGO was blocked by previous application of the $\mu$-selective antagonist CTOP and was dose dependent. This suppression was considered presynaptic because (1) the PPR measured in the striosomes was reversibly and significantly increased by DAMGO, whereas that of the matrix was unchanged; (2) intracellular infusion of GDP- $\beta$-S through the recording patch pipette, which inhibits postsynaptic G-proteins and thus rules out involvement of postsynaptic effects of DAMGO, re-

vealed lack of alteration of inhibition by MOR; and (3) the frequency of mIPSCs in the striosomes but not in the matrix was decreased significantly by DAMGO, whereas amplitudes remained the same in both compartments. Interestingly, larger PPR and a concomitant tendency toward lower frequency of mIPSCs were already noted in the striosomes in the control. The reason for this is unclear. There may not be many GABAergic synapses in the striosomes. Alternatively, this may have been caused by the seemingly protracted development of the striosomal cells, or enkephalin may be tonically released and have partially suppressed GABA release in the control. The latter possibility, however, seems unlikely because the mIPSCs recorded in the presence of an MOR antagonist, CTOP, differed in neither frequency nor amplitude from those recorded without CTOP.

\section{Reciprocal regulation of $\mu$-opioid modulation by PKA and PKC}

There is accumulating evidence that the presynaptic modulation of transmitter release by MOR activation is regulated by enhancement of $\mathrm{K}^{+}$and/or reduction of $\mathrm{Ca}^{2+}$ conductances (Cherubini and North, 1985; Stefani et al., 1994; Endo and Yawo, 2000; Finnegan et al., 2006). Our observation that bath application of 4-AP almost completely blocked the effects of DAMGO strongly suggests that 4 -AP-sensitive $\mathrm{K}^{+}$conductance plays a major role in the presynaptic modulation of IPSCs by MOR. This modulation was found to be mediated by the cAMP-dependent pathway, because application of the adenylyl cyclase inhibitor SQ22536 and the PKA inhibitor H-89 both blocked MOR modulation. Involvement of the arachidonic acid cascade in the presynaptic modulation of IPSCs by MOR appeared unlikely (Vaughan et al., 1997). However, more importantly, the blockade of PKC by previous application of chelerythrine significantly enhanced the presynaptic inhibition of IPSCs by MOR from 20 to 35\%. Thus, transmitters that activate PKC signaling pathways, such as substance $\mathrm{P}$, acetylcholine, and glutamate, may counterbalance the effects of MOR on IPSCs (Bailey et al., 2006).

Another key factor to be considered at the level of striatal local circuits is the source of the intrastriatal GABAergic inputs. The most likely candidate is axon collaterals of other neighboring MS cells. The existence of GABAergic transmission between MS cells has recently been physiologically established using paired recordings in rat slice preparations (Czubayko and Plenz, 2002; Tunstall et al., 2002; Venance et al., 2004). Although collateral inhibition among MS cells is relatively weak when observed from the soma, inhibitory synapses are more common at distal spiny dendrites, and modulation of them might effectively control the membrane excitability of restricted parts of dendrites. The involvement of several types of GABAergic interneurons in the striatum should also be considered. In contrast, MOR-bearing recurrent collaterals from neurons of the globus pallidus, which innervate both compartments, appear unlikely, because no MOR modulation was found in the matrix in our study.

\section{Functional implications}

Roles of opioids in motor control, drug addiction, and Parkinson's disease have been postulated as the basis of autoregulatory mechanisms compensating for excessive activation of the direct and indirect pathway neurons by dopamine and other neurotransmitters (Steiner and Gerfen, 1998; Samadi et al., 2006). Still unclear in this schema is the role of MOR in the striosomes. Enkephalin released as a result of the activities of striatopallidal neurons would presynaptically inhibit GABAergic inputs via MORs, which may be enhanced or weakened by other transmit- 
ters that activate the PKC-dependent pathway in MS cells in the striosomes, where colocalization of MOR is greater with dynorphin than enkephalin (Guttenberg et al., 1996). As suggested by the finding that imbalance in activities of the striosome and matrix compartments predicts motor stereotypy (Canales and Graybiel, 2000; Canales, 2005), presynaptic as well as postsynaptic effects of MORs on MS cells may have profound impacts on activities of the output neurons of the striosomes, eventually changing basal ganglia outputs.

\section{References}

Bailey CP, Smith FL, Kelly E, Dewey WL, Henderson G (2006) How important is protein kinase $\mathrm{C}$ in mu-opioid receptor desensitization and morphine tolerance? Trends Pharmacol Sci 27:558-565.

Barral J, Mendoza E, Galarraga E, Bargas J (2003) The presynaptic modulation of corticostriatal afferents by mu-opioids is mediated by $\mathrm{K}+$ conductances. Eur J Pharmacol 462:91-98.

Canales JJ (2005) Stimulant-induced adaptations in neostriatal matrix and striosome systems: transiting from instrumental responding to habitual behavior in drug addiction. Neurobiol Learn Mem 83:93-103.

Canales JJ, Graybiel AM (2000) A measure of striatal function predicts motor stereotypy. Nat Neurosci 3:377-383.

Cherubini E, North RA (1985) Mu and kappa opioids inhibit transmitter release by different mechanisms. Proc Natl Acad Sci USA 82:1860-1863.

Czubayko U, Plenz D (2002) Fast synaptic transmission between striatal spiny projection neurons. Proc Natl Acad Sci USA 99:15764-15769.

Donoghue JP, Herkenham M (1986) Neostriatal projections from individual cortical fields conform to histochemically distinct striatal compartments in the rat. Brain Res 365:397-403.

Edley SM, Herkenham M (1984) Comparative development of striatal opiate receptors and dopamine revealed by autoradiography and histofluorescence. Brain Res 305:27-42.

Endo K, Yawo H (2000) mu-Opioid receptor inhibits $\mathrm{N}$-type $\mathrm{Ca}^{2+}$ channels in the calyx presynaptic terminal of the embryonic chick ciliary ganglion. J Physiol (Lond) 524:769-781.

Finnegan TF, Chen SR, Pan HL (2006) Mu opioid receptor activation inhibits GABAergic inputs to basolateral amygdala neurons through Kv1.1/1.2 channels. J Neurophysiol 95:2032-2041.

Fishell G, van der Kooy D (1987) Pattern formation in the striatum: developmental changes in the distribution of striatonigral neurons. J Neurosci 7:1969-1978.

Gerdeman GL, Partridge JG, Lupica CR, Lovinger DM (2003) It could be habit forming: drugs of abuse and striatal synaptic plasticity. Trends Neurosci 26:184-192.

Gerfen CR (1992) The neostriatal mosaic: multiple levels of compartmental organization. Trends Neurosci 15:133-139.

Graybiel AM (1990) Neurotransmitters and neuromodulators in the basal ganglia. Trends Neurosci 13:244-254.

Graybiel AM, Ragsdale Jr CW (1978) Histochemically distinct compartments in the striatum of human, monkeys, and cat demonstrated by acetylthiocholinesterase staining. Proc Natl Acad Sci USA 75:5723-5726.

Graybiel AM, Pickel VM, Joh TH, Reis DJ, Ragsdale Jr CW (1981) Direct demonstration of a correspondence between the dopamine islands and acetylcholinesterase patches in the developing striatum. Proc Natl Acad Sci USA 78:5871-5875.

Guttenberg ND, Klop H, Minami M, Satoh M, Voorn P (1996) Colocalization of mu opioid receptor is greater with dynorphin than enkephalin in rat striatum. NeuroReport 7:2119-2124.

Herkenham M, Pert CB (1981) Mosaic distribution of opiate receptors, parafascicular projections and acetylcholinesterase in rat striatum. Nature 291:415-418.

Hsu KS, Yang CH, Huang CC (1997) Carbachol induces inward current in rat neostriatal neurons through a G-protein-coupled mechanism. Neurosci Lett 224:79-82.

Jiang ZG, North RA (1992) Pre- and postsynaptic inhibition by opioids in rat striatum. J Neurosci 12:356-361.

Kawaguchi Y, Wilson CJ, Emson PC (1989) Intracellular recording of identified neostriatal patch and matrix spiny cells in a slice preparation preserving cortical inputs. J Neurophysiol 62:1052-1068.

Levesque M, Wallman MJ, Parent A (2004) Striosomes are enriched in glutamic acid decarboxylase in primates. Neurosci Res 50:29-35.
Liu X, Wang Q, Haydar TF, Bordey A (2005) Nonsynaptic GABA signaling in postnatal subventricular zone controls proliferation of GFAPexpressing progenitors. Nat Neurosci 8:1179-1187.

Mansour A, Fox CA, Akil H, Watson SJ (1995) Opioid-receptor mRNA expression in the rat CNS: anatomical and functional implications. Trends Neurosci 18:22-29.

Matsushita N, Okada H, Yasoshima Y, Takahashi K, Kiuchi K, Kobayashi K (2002) Dynamics of tyrosine hydroxylase promoter activity during midbrain dopaminergic neuron development. J Neurochem 82:295-304.

Miura M, Watanabe M, Offermanns S, Simon MI, Kano M (2002) Group I metabotropic glutamate receptor signaling via $\mathrm{G} \alpha \mathrm{q} / \mathrm{G} \alpha 11$ secures the induction of long-term potentiation in the hippocampal area CA1. J Neurosci 22:8379-8390.

Narushima M, Uchigashima M, Fukaya M, Matsui M, Manabe T, Hashimoto K, Watanabe M, Kano M (2007) Tonic enhancement of endocannabinoid-mediated retrograde suppression of inhibition by cholinergic interneuron activity in the striatum. J Neurosci 27:496-506.

Norenberg W, Wirkner K, Illes P (1997) Effect of adenosine and some of its structural analogues on the conductance of NMDA receptor channels in a subset of rat neostriatal neurones. Br J Pharmacol 122:71-80.

Ohno-Shosaku T, Matsui M, Fukudome Y, Shosaku J, Tsubokawa H, Taketo MM, Manabe T, Kano M (2003) Postsynaptic M1 and M3 receptors are responsible for the muscarinic enhancement of retrograde endocannabinoid signalling in the hippocampus. Eur J Neurosci 18:109-116.

Samadi P, Bedard PJ, Rouillard C (2006) Opioids and motor complications in Parkinson's disease. Trends Pharmacol Sci 27:512-517.

Schneider SP, Eckert III WA, Light AR (1998) Opioid-activated postsynaptic, inward rectifying potassium currents in whole cell recordings in substantia gelatinosa neurons. J Neurophysiol 80:2954-2962.

Shin RM, Masuda M, Miura M, Sano H, Shirasawa T, Song WJ, Kobayashi K, Aosaki T (2003) Dopamine $\mathrm{D}_{4}$ receptor-induced postsynaptic inhibition of GABAergic currents in mouse globus pallidus neurons. J Neurosci 23:11662-11672.

Stefani A, Surmeier DJ, Bernardi G (1994) Opioids decrease high-voltage activated calcium currents in acutely dissociated neostriatal neurons. Brain Res 642:339-343.

Steiner H, Gerfen CR (1998) Role of dynorphin and enkephalin in the regulation of striatal output pathways and behavior. Exp Brain Res 123:60-76.

Tepper JM, Sharpe NA, Koos TZ, Trent F (1998) Postnatal development of the rat neostriatum: electrophysiological, light- and electron-microscopic studies. Dev Neurosci 20:125-145.

Tunstall MJ, Oorschot DE, Kean A, Wickens JR (2002) Inhibitory interactions between spiny projection neurons in the rat striatum. J Neurophysiol 88:1263-1269.

Vaughan CW, Ingram SL, Connor MA, Christie MJ (1997) How opioids inhibit GABA-mediated neurotransmission. Nature 390:611-614.

Venance L, Glowinski J (2003) Heterogeneity of spike frequency adaptation among medium spiny neurones from the rat striatum. Neuroscience 122:77-92.

Venance L, Glowinski J, Giaume C (2004) Electrical and chemical transmission between striatal GABAergic output neurones in rat brain slices. J Physiol (Lond) 559:215-230.

Walker RH, Arbuthnott GW, Baughman RW, Graybiel AM (1993) Dendritic domains of medium spiny neurons in the primate striatum: relationships to striosomal borders. J Comp Neurol 337:614-628.

Wang H, Pickel VM (1998) Dendritic spines containing mu-opioid receptors in rat striatal patches receive asymmetric synapses from prefrontal corticostriatal afferents. J Comp Neurol 396:223-237.

Wang H, Pickel VM (2001) Preferential cytoplasmic localization of deltaopioid receptors in rat striatal patches: comparison with plasmalemmal $\mu$-opioid receptors. J Neurosci 21:3242-3250.

Wang H, Moriwaki A, Wang JB, Uhl GR, Pickel VM (1996) Ultrastructural immunocytochemical localization of mu opioid receptors and Leu5enkephalin in the patch compartment of the rat caudate-putamen nucleus. J Comp Neurol 375:659-674.

White NM, Hiroi N (1998) Preferential localization of self-stimulation sites in striosomes/patches in the rat striatum. Proc Natl Acad Sci USA 95:6486-6491.

Wilson CJ (2004) Basal ganglia. In: The synaptic organization of the brain, Ed 5 (Shepherd GM, ed), pp 361-414. Oxford: Oxford UP.

Winzer-Serhan UH, Chen Y, Leslie FM (2003) Expression of opioid peptides and receptors in striatum and substantia nigra during rat brain development. J Chem Neuroanat 26:17-36. 